
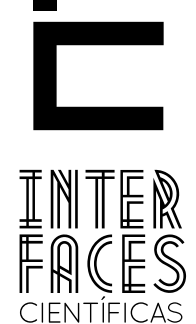

DIREITO

\title{
A AMPLA POSSIBILIDADE DE ADOÇÃO POR CASAIS HOMOAFETIVOS FACE ÀS RECENTES DECISÕES DOS TRIBUNAIS SUPERIORES
}

César Augusto de Castro Fiúza ${ }^{1}$
Luciana Costa Poli

\section{RESUMO}

O trabalho analisa a possibilidade de adoção conjunta por núcleos familiares formados por pessoas do mesmo sexo, considerando a decisão do STF na ADPF 132 e da ADI 4277, que atribui a essas uniões os efeitos jurídicos da união estável. Pretende-se, no presente trabalho, apresentar o instituto da adoção no Brasil a partir da concepção pluralista de família e buscar compreender o alcance da decisão do STF, debatendo alguns votos considerados controvertidos. Abordaremos ainda a formação da família contemporânea, buscando delinear um conceito de família que se aproxima dos ideários do Estado Democrático de Direito. 0 artigo buscará fazer uma releitura da família a partir da principiologia constitucional, em especial, os prin- cípios da dignidade da pessoa humana, da liberdade, da isonomia, do tratamento não discriminatório, da pluralidade das formas familiares. Procurar-se-á defender, que a família formada por pares homossexuais merece ampla equiparação à união estável heterossexual. Apresenta-se a adoção como meio de se permitir o desenvolvimento da criança em um ambiente familiar saudável, dando azo ao princípio do melhor interesse da criança.

\section{PALAVRAS-CHAVE:}

Adoção. União Homoafetiva. União Estável. Melhor Interesse da Criança. Família. 


\section{ABSTRACT}

This paper investigates the possibility of joint adoption by households formed by people of the same sex, according to the Supreme Court's ADPF 132 and ADI 4277, which attaches to these unions the legal effects of a stable union. It is intended, in this paper, to present the institution of adoption in Brazil from the pluralist conception of family and to analyze the scope of the decision of the Supreme Court, arguing some votes considered controversial. The contemporary family formation was also discussed, trying to define a concept of family that is close to the ideals of the democratic rule of law. The article will try to reread the family from the constitutional principles, in particular the principles of human dignity, freedom, equality, non-discriminatory treatment, the plurality of family forms. It will be defended that the family formed by homosexual couples deserves the same treatment, concerning union estability, which is observed with the heterosexual couples. The adoption is presented as a means of allowing the development of the child in a healthy familiar environment, valuing the principle of the best interests of the child.

\section{KEYWORDS}

Adoption. Gay Marriage. Stable Uninon. Best Interest of the Child. Family.

\section{INTRODUÇ̄̃̃O}

0 tema central a ser abordado é a possibilidade de adoção conjunta por núcleos familiares formados por pessoas do mesmo sexo, considerando a decisão do STF na ADPF 132 e da ADI 4277, que atribui a essas uniões os efeitos jurídicos da união estável.

Todos os dez Ministros votantes no referido julgamento manifestaram-se pela procedência das

\section{RESUMEN}

En este trabajo se investiga la posibilidad de adopción conjunta por personas del mismo sexo, mientras que en ADPF del Tribunal Supremo 132 y ADI 4277, que concede a estas uniones los efectos jurídicos de una unión estable. Se pretende, en este trabajo presentar la institución de la adopción en Brasil de la concepción pluralista de la familia y tratar de comprender el alcance de la decisión de la Corte Suprema, argumentando algunos votos objeto de polémica. También abordaremos la formación de la familia contemporánea, para definir un concepto de familia que está cerca de los ideales de un Estado democrático de derecho. El artículo intenta releer la familia a partir de los principios constitucionales, en particular los principios de la dignidad humana, libertad, igualdad, trato no discriminatorio, la pluralidad de formas familiares. Se busca defender que la familia formada por parejas homosexuales se merecen el mismo trato que la heterosexual estable. Se presenta la adopción como una forma de permitir el desarrollo del niño en un ambiente familiar sano, dando lugar al principio del interés superior del niño

\section{PALABRAS CLAVE}

Adopción. Unión Homosexual. Unión Estable. Mejor Interés del Niño. Familia.

respectivas ações constitucionais, reconhecendo a união homoafetiva como entidade familiar e aplicando a ela o regime concernente à união estável entre homem e mulher, regulada no art. 1.723 do Código Civil brasileiro. Reconheceu-se que a união homoafetiva é um modelo familiar, vislumbrando-se a necessidade de repressão a todo e qualquer tipo de discriminação. 
Alguns votos tiveram como fundamentação a interpretação conforme a Constituição, de acordo com o pedido formulado na petição inicial de ambas as ações. Outros votos divergiram, apontando que a união entre pessoas do mesmo sexo não poderia ser considerada união estável, devendo, ao revés, ser considerada outro tipo familiar.

Apontou-se, no referido julgado, que a constitucionalidade da união homoafetiva como entidade familiar possuía sustentáculo nos direitos fundamentais. Argumentou-se também no sentido de existir uma lacuna legislativa, que deveria ser suprida por meio da analogia com o instituto mais aproximado: a união estável e, por fim, ainda existiu entendimento de que se deveria aplicar extensivamente o regime jurídico da união estável. Alguns desses entendimentos serão enfrentados nesse trabalho.

Certo é que, com argumentos ora convergentes, ora divergentes na fundamentação dos seus votos, os Ministros do Supremo Tribunal Federal brasileiro outorgaram o "selo" de família às uniões homoafetivas e entenderam que estas se submetem ao regime da união estável, de que decorre uma vasta gama de direitos e deveres ${ }^{1}$.

Diante desse quadro, pretende-se no presente trabalho, apresentar o instituto da adoção no Brasil a partir da concepção pluralista de família e buscar compreender o alcance da decisão do STF, debatendo alguns pontos que consideramos controvertidos nos votos dos ministros, na histórica decisão.
Abordaremos, ainda que de forma breve, a formação da família contemporânea, buscando delinear um conceito de família que se aproxima dos ideários do Estado Democrático de Direito.

A releitura da família ora proposta terá como cerne a principiologia constitucional, em especial, os princípios da dignidade da pessoa humana, da liberdade, da isonomia, do tratamento não discriminatório, da pluralidade das formas familiares.

Nesse diapasão, procurar-se-á defender, que a família formada por pares homossexuais merece ampla equiparação à união estável heterossexual, ao contrário de algumas vozes do STF, que destacam o elemento sexual como determinante na formação de um núcleo familiar.

A proposta de tratamento peculiar às uniões homoafetivas, no nosso entender, além de inútil, acaba por ser discriminatória, e pode suscitar restrições à atribuição dos efeitos jurídicos da união estável a essas uniões.

Enfim, o que se pretende com o presente trabalho é procurar demonstrar que a decisão do STF deve ser interpretada de forma ampla, possibilitando a atribuição de todos os direitos inerentes à união estável, também à união formada por pessoas do mesmo sexo.

Procura-se defender que a adoção deve se dar sempre de modo a permitir o desenvolvimento da criança em um ambiente familiar saudável, dando azo ao princípio do melhor interesse da criança, e que a existência de "dois pais" ou "duas mães" não importa prejuízo para o adotado. 


\section{A AMPLA POSSIBILIDADE DE ADOÇÃO POR CA- SAIS HOMOAFETIVOS FACE ÀS RECENTES DECl- SÕES DOS TRIBUNAIS SUPERIORES}

Desde a Antiguidade, além da filiação biológica, concebeu-se outro modelo de parentalidade-filiação não natural ou decorrente de uma ficção jurídica (GAMA, 2001, p. 412). Nessa época, havia a permissão da continuidade da família não fundada na consanguinidade, ou seja, o instituto da adoção decorria não de um ato de amor, mas da necessidade de se perpetuar o fogo sagrado e o culto da família que seria interrompido caso não houvesse descendentes. Em outras palavras, a ideia era a de se dar um filho a quem não o tivesse.

Segundo Coulanges (1950, p. 72), na sociedade romana, em cada casa havia um altar e em torno dele, a família reunida, ali se encontrava ao amanhecer e ao anoitecer para dirigir ao fogo sagrado, as primeiras e as últimas orações do dia e ainda para compartilhar entre seus membros as refeições, cantos e atos religiosos.

A família era compreendida neste tempo não apenas por aqueles ali presentes, mas reunia também os antepassados, diariamente cultuados em seus túmulos, parte fundamental de toda morada. 0 princípio da família antiga não estava unicamente na geração, não estava no afeto natural, não estava no sangue, daí porque as leis dessas sociedades estavam em contraposição ao afeto natural e à ordem de nascimento.

O que estabelecia laços de família nas sociedades antigas era a religião do lar e dos antepassados, formando-se assim, uma sociedade religiosa e, concomitantemente, familiar (COULANGES, 1950, p. 73). Após a morte, o homem era considerado um ser feliz e divino, desde que seus sucessores lhe oferecessem a refeição fúnebre e as orações diárias. Caso essas oferendas não fossem realizadas, o morto cairia em desgraça. Traço marcante da família antiga, tal necessidade imposta pela religião de sua continuidade para a perpetuação do culto.

Era dever do homem, preocupar-se com sua descendência, razão pela qual o celibato era considerado grave impiedade e desgraça, tendo sido considerado punível. 0 filho que poderia perpetuar a religião doméstica deveria ser fruto do casamento religioso, o laço de sangue por si só não constituía para o filho o liame de membro da família. 0 casamento tinha o objetivo de garantir a continuidade da família. Caso a mulher não conseguisse gerar filhos, era possível anular-se a união matrimonial ou divorciar-se, para que ao homem se permitisse uma nova união fértil. Em caso de morte do marido, a mulher deveria casar-se com o irmão do falecido ou com outro parente próximo, e se considerava o filho daquela união perpetuador do culto doméstico.

Importante apontar que a descendência desejada era a masculina, não preenchendo o objetivo do casamento o nascimento de filha, eis que esta não poderia perpetuar o culto familiar, já que com seu próprio casamento passaria a pertencer ao culto do marido (COULANGES, 1950, p. 73). As filhas eram importantes do ponto de vista das alianças políticas do pai, uma vez que os casamentos eram arranjados.

Por sua vez, a adoção contemporânea é ato de desprendimento, de amor, é uma filiação jurídica que se fundamenta na afetividade. Para alguns, é ato ou negócio jurídico que cria relações de filiação e de paternidade (VENOSA, 2005, p. 148); para outros, consiste na escolha de tornar-se pai e/ou mãe de alguém com quem, geralmente não haja vínculo biológico algum (ALMEIDA, 2010, p. 395). Trata-se, sem dúvidas, de 
um parentesco eletivo (DIAS, 2007, p. 426), que decorre exclusivamente de um ato de vontade, da vontade afetiva que desencadeia efeitos jurídico-familiares. Se antes a adoção implicava dar um filho a quem não o tinha, hoje implica dar pais a quem não os tem, ou melhor, dar família a quem não a tem.

A adoção significa assumir a paternidade/maternidade de um indivíduo, com o qual, não haja a princípio, liame biológico ${ }^{2}$. Segundo Venosa (2010, p. 148), "é modalidade artificial de filiação que busca imitar a filiação natural” (DIAS, 2007, p. 426). A adoção é também conhecida como colocação em família substituta, e pressupõe a desconstituição do poder familiar dos pais biológicos.

A adoção, também conhecida como filiação civil, é tratada expressamente pela $C R / 88^{3}$, que proíbe qualquer espécie de distinção entre os filhos. A disciplina legal da adoção encontra-se no CC/2002, com a redação dada pela Lei 12.010/2009, e na Lei 8.069/90 - o ECA, que adota a teoria da proteção integral e do melhor interesse da criança e do adolescente. Na concepção de Venosa (2010, p. 148), a Lei 12.010/2009 introduziu profunda alteração na sistemática do instituto, adaptando o ECA e derrogando o CC/2002, na parte referente ao tema.

Em Portugal, a adoção é prevista no CCP, art. $1.586^{\circ},{ }^{4}$ mas, Duarte Pinheiro (2011, p. 203) propõe um conceito mais abrangente: "vínculo constituído por sentença judicial proferida no âmbito de um processo especialmente instaurado para o efeito, que, independentemente dos laços de sangue, cria direitos e deveres paterno-filiais (em sentido lato) entre duas pessoas".

20 art. 42 do ECA não permite a adoção aos ascendentes e irmãos do adotando, permite a adoção de tios e primos do adotando, preenchidos os pressupostos legais.

3 Ar. 227, §5o, ao estabelecer: “A adoção será assistida pelo Poder Público na forma da lei que estabelecerá casos e condições de sua efetivação por parte de estrangeiros."

4 Art. 1.586o. A adoção é o vínculo que, à semelhança da filiação natural, mas independentemente dos laços de sangue, se estabelece legalmente entre duas pessoas nos termos dos arts. 1.9730 e seguintes.
É interessante a crítica que Duarte Pinheiro (2011, p. 208) tece sobre o instituto. Segundo sua concepção, a filiação adotiva, dado seu caráter excepcional, é tratada pelo ordenamento jurídico como secundária, subsidiária, de segunda classe, em relação à filiação biológica. Excepcionalidade que, no plano jurídico, se confirma no sistema português, ao consagrar constitucionalmente o princípio da inseparabilidade dos filhos dos pais, princípio aplicável aos pais biológicos, só sendo afastado se comprovado que não cumpriram seus deveres fundamentais.

Tal imitação, continua o autor, reflete-se num momento subsequente na preferência por espécies de adoção que acabam por reduzir as possibilidades de constituição do vínculo adotivo: a adoção conjunta é tida como adoção superior à singular; a adoção por pessoas do mesmo sexo é absolutamente rejeitada pelo ordenamento jurídico português ${ }^{5}$. Aos homossexuais resta apenas a adoção singular, o que resulta num número relativamente limitado de adoções por homossexuais, dada a preferência pela adoção conjunta (DUARTE PINHEIRO, 2011, p. 203).

Tal questão tem gerado grande polêmica em Portugal e será debatida no Parlamento. Portugal é o único país em que pessoas do mesmo sexo podem casar, mas não adotar. Segundo Duarte Pinheiro (2011, p. 208), a permissão do casamento entre pessoas do mesmo sexo "introduziu uma nova discriminação para os casais homossexuais e não atende ao superior interesse das crianças".

No Brasil, diferentemente de Portugal ${ }^{6}$, que restringe a adoção a crianças, qualquer pessoa pode ser adotada, seja menor ou maior de idade (ALMEIDA, RODRIGUES, 2010, p. 396). Para ser adotante é

5 Lei n. 9/2010, art. 3. Essa lei veio a permitir o casamento civil entre pessoas do mesmo sexo, mas negou a faculdade de adoção conjunta às pessoas casadas com cônjuges do mesmo sexo e não pretendeu modificar as regras atinentes à filiação não adotiva.

60 requisito da idade máxima do adotado figura no art. 1980, n, 2 do CCP que estipula que em regra o adotando deve ter menos de 15 anos à época da petição judicial de adoção. 
exigida a maioridade civil e a diferença mínima de idade de 16 anos em relação ao adotado. Na legislação portuguesa, em regra, a idade mínima é 25 anos e a máxima, 60 anos (DUARTE PINHEIRO, 2010, p. 214). Para a adoção individual, é irrelevante o estado civil do adotante ${ }^{7}$; já a adoção conjunta requer a existência de relação familiar entre os adotantes, em regra, relação afetiva atual, ainda que a Lei permita excepcionalmente a adoção, quando a relação já tenha terminado.

A questão central a ser discutida no presente trabalho, no que se refere à adoção é a seguinte: ainda que o art. 1.622 do Código Civil e o $\S 2^{\circ}$ do art. 42 do ECA prescrevam que a adoção conjunta possa ser feita por duas pessoas unidas pelo vínculo do casamento ou que formem união estável, estes dispositivos legais não devem ser interpretados mais em sua literalidade, considerando os recentíssimos julgados do STJ e do $\mathrm{STF}^{8}$, que atribuíram à união homoafetiva os efeitos da união estável.

O STJ já reconheceu, por unanimidade, a possibilidade de adoção conjunta de crianças por pares homoafetivos $^{9}$, que com maior frequência recorrem ao Judiciário para que, com o intuito de salvaguardar direitos do próprio adotado, possa estender a adoção ao par, e não apenas efetivar a adoção individual por um de seus membros.

A questão ganhou novo fôlego com a decisão do STF, de atribuir às uniões homoafetivas a qualidade de união estável. O STF, como já se teve a oportunidade de ressaltar, na Ação Direta de Inconstitucionalidade n. 4277/Arguição de Descumprimento de Preceito Fundamental n. 132, discutiu a interpretação legitimadora do art. 1.723 do Código Civil, no sentido de permitir a declaração de sua incidência também na união de pessoas do mesmo sexo, de natureza públi-

7 Bem como é irrelevante o fato de manter união afetiva estável.

8 Ação Direta de Inconstitucionalidade n. 4277/Arguição de Descumprimento de Preceito Fundamental n. 132

9 Resp. 889.852-RS ( 2006/0209137-4). Rel. Min. Luis Felipe Salomão, DJ $10 / 08 / 2010$, julgamento 27 de abril de 2010 . ca, contínua e duradoura, formada com o objetivo de constituir família.

Registre-se que o voto do Ministro Ricardo Lewandowisk destacou que devem ser aplicadas às uniões homoafetivas, caracterizadas como entidades familiares, as prescrições legais relativas à união estável, excluídas aquelas que exijam a diversidade de sexo para o seu exercício, até que sobrevenham disposições normativas específicas sobre o tema.

Diante desse entendimento, dúvidas podem surgir sobre a possibilidade de adoção por pares homossexuais, já que a Lei 12.010/2009, já citada, restringe a adoção conjunta a pessoas casadas ou que vivam em união estável.

Isso porque, o citado Ministro entende que a união homoafetiva constituiria uma espécie distinta de família, o que implicaria a necessidade de uma legislação específica sobre o tema. Segundo Lewandowisk, embora a união homoafetiva possa caracterizar-se como união familiar, se presentes os requisitos da estabilidade, ostensibilidade e publicidade, não poderia ser equiparada à união estável, por se tratar de união entre pessoas de gênero igual.

Conclui seu voto reafirmando que o emprego da analogia nesse caso aplica-se tão somente às situações assemelhadas, descartando-se aquelas que são próprias das relações entre pessoas do mesmo sexo.

Esse raciocínio, segundo nossa opinião, não deve prevalecer, uma vez que o elemento sexual não constitui aspecto relevante na formação de um núcleo familiar. Tratar a união familiar formada por pessoas do mesmo sexo como uma possível quarta forma de família, como sugere o Ministro, parece-nos desnecessário e discriminatório, pois faria alusão a uma forma de família distinta unicamente, como admite o próprio Ministro por uma "diferença singela", ou seja, a condição sexual. 
A homofobia, discriminatória em sua essência, muitas vezes busca legitimar-se num aparente discurso de legalidade. É a chamada homofobia liberal. Tolerância é sua palavra de ordem. Mas, há grande distância entre tolerar e reconhecer. Uma coisa é tolerar comportamentos íntimos, outra bem diferente é reconhecer direitos iguais (BORRILO, 2010, p. 76).

Os homossexuais não demandam direitos ou proteção "especiais". A CR/88 já lhes permitia enquadrar os seus argumentos em termos de igualdade, em vez de diferença, em termos de liberdade, cidadania e dignidade. Os homossexuais estão a pedir nada a mais do que os heterossexuais já têm desde sempre: a liberdade de constituir-se como família e, consequentemente, todos os direitos daí decorrentes, inclusive a adoção conjunta e a possibilidade de casamento.

Apenas para ilustrar, a opinião de Múrias (2008, p. 11-67) acentua que um casal de pessoas do mesmo sexo pode pretender a constituição da relação simbólica do casamento, num exercício idêntico ao de um casal de sexo diferente. Um casal que queira casar pretende a inclusão formal no âmbito de aplicação da linguagem própria do casamento e pretende, com isso, o acesso às representações e às expectativas sociais típicas do casamento, as representações e expectativas típicas do amor, compromisso, família e constituição de família, publicidade, oficialização, exclusividade, coabitação e economia comum. 0 estatuto global correspondente a estas representações não pode ser obtido senão pelo casamento.

A família atual transcendeu de uma concepção fundada nas preferências ou condições sexuais para uma concepção mais solidarista, como núcleo de cooperação, de fomento ao pleno desenvolvimento da personalidade de seus membros. Nesse sentido, não se compreende o afeto ou a condição sexual como norteadores das relações familiares, pois a realização das aspirações afetivas e sexuais se dará ou não, porém, a família talvez possa ser compreendida não apenas como núcleo de afeto, mas como espaço de cooperação, ajuda mútua, comunidade voltada à realização e promoção da dignidade humana, ainda que não vocacionada ao amor.

Certo é que não se pretende atribuir à família o viés de unidade proposta ou imposta para realização exclusiva de fins econômicos, políticos, religiosos e sociais. Defende-se a livre escolha do indivíduo para constituir um agrupamento de companheirismo e afetividade; mas, porque não também de cooperação econômica, psicológica, social e não pautada exclusivamente no afeto ou na condição sexual?

O comprometimento com os princípios constitucionais, em especial a dignidade da pessoa humana e a pluralidade da família, nos conduz a compreender a família (VILLELA, 1980, p. 11) funcionalizada como instrumento de concretização da liberdade, como ressalta Perlingieri: "A liberdade na família encontra na unidade e nos relativos deveres não apenas o limite, mas a função, o fundamento para a própria titularidade" (2002, p. 125).

Ademais disso, o ponto nuclear dos dispositivos em questão é a comprovação da estabilidade da família, ou seja, indispensável é a existência de ambiente familiar saudável, independentemente da roupagem que possa assumir.

Como já salientado acima, a legislação permite a adoção conjunta das pessoas separadas ou divorciadas, desde que o estágio de convivência tenha se iniciado no período da convivência conjugal ou da união estável, e desde que haja acordo sobre a guarda e direito de visitas. Na realidade, a própria lei admite a adoção conjunta, ainda que inexistente qualquer liame legal ou afetivo. Portanto, a negativa desse direito ao par homossexual reflete tão somente um entendimento apressado e preconceituoso (homofóbico) do texto legal (DIAS, 2007, p. 439).

Outro ponto fundamental ao deslinde da questão: a adoção se fará tendo em vista em primeiro lugar os 
interesses do adotado, em atendimento ao princípio do melhor interesse da criança. Isso equivale a dizer que importante é a estabilidade do lar em que será introduzido o menor, as possibilidades que lhe serão dadas de receber assistência econômica e, sobretudo, afetiva ${ }^{10}$. É a possibilidade de lhe ser atribuído um lar, uma família, um núcleo de amor, cuidado e carinho. Esta é a razão principal da adoção, que não justifica o entendimento de que apenas as famílias heterossexuais, formadas pelo casamento ou pela união estável são capazes de proporcionar.

A negativa da medida de adoção só deve ocorrer, quando comprovado concretamente que não serão atendidos os interesses do menor, independentemente do arranjo familiar. A solução a ser encontrada deve privilegiar a proteção dos direitos das crianças e adolescentes, conforme determina o art. 43 do $\mathrm{ECA}^{11}$.

Não existe nenhum óbice legal ou inconveniente de ordem psicológica ou sociológica a afastar a possibilidade de adoção por casal homoafetivo. Medina (2008, p. 324) reporta estudos realizados pela Universidade de Valencia e pela Academia Americana de Pediatria que concluem que a opção sexual dos adotantes em nada prejudica o desenvolvimento psicossocial do adotado ${ }^{12}$.

Ao contrário, tais adoções implicam maior segurança, amparo e afeto a crianças que seriam confinadas à impessoalidade das instituições públicas. Sendo assim, se os estudos científicos ${ }^{13}$ não apontam

100 art. 10 da Lei 12.010/09 prevê a garantia do direito a convivência familiar a todas as crianças e adolescentes.

11 "Art. 43. A adoção deve ser deferida quando apresentar reais vantagens para o adotado e fundar-se em motivos legítimos."

12 A autora resume da seguinte forma as conclusões das referidas pesquisas: ser pai ou ser mãe não está tanto no fato de gerar, quanto na circunstância de amar e servir; nem sempre, na definição dos papéis maternos e paternos há coincidência do sexo biológico com o sexo social; os comportamentos de crianças criadas em lares homossexuais não variam fundamentalmente daqueles da população em geral; as crianças que crescem com pais gays ou lésbicas se desenvolvem tão bem sob os aspectos emocional, cognitivo, social e do funcionamento sexual quanto a criança cujos pais são heterossexuais. Tradução livre.

13 Também nesse sentido o STJ já se manifestou, afirmando que diversos e respeitados estudos especializados sobre o tema realizados pela Universidade de Valência, na Universidade de Virgínia e Academia Americana de prejuízo de qualquer natureza para as crianças na adoção por pares homoafetivos, e desde que realizados os estudos psicossociais previstos na legislação, há que garantir o direito constitucional à convivência familiar e aplicação do princípio do melhor interesse da criança ${ }^{14}$

O não reconhecimento do direito de adoção às famílias homoafetivas poderia levar a criança adotada unilateralmente a se sentir discriminada e estigmatizada, não por pertencer a este grupo familiar, mas por se sentir excluída pelo ordenamento jurídico que não reconhece sua situação familiar (FARIAS, MAIA, 2008, p. 217). O problema, repita-se, é a homofobia, não a homossexualidade. Se o que se busca com a adoção é a preservação do melhor interesse da criança, seu bem estar, pode-se concluir que se houver impossibilidade de se facultar a adoção a ambos os parceiros na união homoafetiva, a criança adotada apenas por um deles estará em situação marginalizada e discriminada.

Vale lembrar que, além dos imensuráveis prejuízos psicológicos e afetivos, a negativa do direito de filiação a estas crianças acarreta-lhes prejuízos de ordem material (sucessão, alimentos, inclusão no plano de saúde, pensão previdenciária, dentre outros), já que a adoção conjunta implica assunção de responsabilidade parental solidária pelos adotantes e, por conseguinte, maior garantia de ordem econômica ao adotado.

Por fim, não se pode usar como argumento con-

Pediatria não indicam qualquer inconveniente na adoção por casais homossexuais, importando mais a qualidade do vínculo e do afeto do meio familiar a ser inserida a criança. Resp. 889.852-RS (2006/0209137-4). Rel. Min. Luis Felipe Salomão, DJ 10/08/2010, julgamento 27 de abril de 2010.

14 Art. $3^{\circ}$. A criança e o adolescente gozam de todos os direitos fundamentais inerentes à pessoa humana, sem prejuízo da proteção integral de que trata esta Lei, assegurando-se-lhes, por lei ou por outros meios, todas as oportunidades e facilidades, a fim de lhes facultar o desenvolvimento físico, mental, moral, espiritual e social, em condições de liberdade e de dignidade.

Art. $4^{\circ}$ É dever da família, da comunidade, da sociedade em geral e do poder público assegurar, com absoluta prioridade, a efetivação dos direitos referentes à vida, à saúde, à alimentação, à educação, ao esporte, ao lazer, à profissionalização, à cultura, à dignidade, ao respeito, à liberdade e à convivência familiar e comunitária. 
trário à adoção por casal homoafetivo, a impossibilidade de registro do filho, pois nada impede a simples menção dos "pais" atendida a ordem alfabética e respectiva filiação biológica (avós) (PEREIRA, 2006c, p. 422). Afirma Dias (2010, p. 439) que a Lei 6.015/73 não pode ser considerada um obstáculo, e não proíbe expressamente que se mencione na certidão os nomes dos pais ou das mães. A inexistência de previsão expressa da inclusão dos nomes dos pais ou mães da criança pela Lei 6.015/73 não pode ser óbice à proteção das crianças e dos adolescentes, considerado o enfoque conferido pelo ECA e pela Lei 12.109/2009 do princípio do melhor interesse da criança. E mais, o legislador não quis utilizar nos diplomas legais ora mencionados expressão restritiva de modo a excluir definitivamente da abrangência legal a união homoafetiva.

É por vezes questionado se a ausência de modelo do gênero masculino e feminino pode eventualmente tornar confusa a própria identidade sexual, havendo o risco de o adotado tornar-se homossexual. Também causa apreensão a possibilidade de o filho ser alvo de repúdio no meio escolar, o que poderia lhe acarretar perturbações psicológicas ou problemas de inserção social.

Essas preocupações, no entanto, são afastadas com segurança por quem se debruça no estudo das famílias homoafetivas com prole, conforme relata Medina (2008, p. 224). As evidências trazidas pelas pesquisas, não permitem vislumbrar a possibilidade de ocorrência de distúrbios ou desvios de conduta pelo fato de alguém ter dois pais ou duas mães, prossegue a autora.

Ser pai ou mãe representa uma função que não está ligada à figura física (PEREIRA, 2006c, p. 638) ${ }^{15}$, o vínculo de parentalidade é estabelecido pela iden-

15 Anota Pereira que é possível no Direito de Família Contemporâneo compreender que a paternidade seja uma função, e em razão disto se desenvolveu a teoria da paternidade desbiologizada ou socioafetiva. Por isso, ser pai é uma representação simbólica, e o que interessa para a existência do sujeito não é propriamente o pai, mas um pai. tificação do papel exercido pelo indivíduo em relação à criança e pela forma como a criança identifica esta figura. A família é uma estruturação psíquica (LACAN, 2002, p. 14 $)^{16}$, em que cada um de seus membros ocupa um lugar, exerce uma função (PEREIRA, 2006b, p. 152-159). O critério de aferição da parentalidade é a afetividade, elemento estruturante da filiação adotiva. Relata Medina (2008, p. 324) que os estudos realizados pela Universidade de Virgínia apontam que:

- $\quad$ ser pai ou mãe não esta tanto no fato de gerar, mas principalmente na circunstância de amar;

- nem sempre na definição dos papéis paternos e maternos há coincidência entre o sexo biológico e o desempenhado socialmente;

- as crianças que crescem num lar homoafetivo não necessariamente apresentam problemas relacionados a isso;

- não há dados ou justificativas que comprovem que pessoas homossexuais não possam desempenhar adequadamente o papel de pais ou mães, de modo a afetar o desenvolvimento psicossocial dos filhos;

- educar e criar os filhos de forma saudável não implica criação e educação heterossexual;

- criança que cresce com um ou dois pais, ou mães homossexuais se desenvolvem tão bem sob o aspecto emocional, cognitivo e do funcionamento sexual quanto a criança de família heterossexual;

- não foram constatados quaisquer efeitos danosos ao normal desenvolvimento ou à estabilidade emocional decorrentes do convívio de

16 Para a psicanálise, a família não é um grupo natural, mas cultural, não se construindo por homem, mulher e filhos. Consiste, ao revés, numa edificação psíquica, em que cada membro ocupa um lugar/função de pai, de mãe, de filho, sem que haja necessidade de vínculo biológico. 
crianças com pais do mesmo sexo;

- também não há registro de dano sequer potencial ou risco ao sadio estabelecimento dos vínculos afetivos;

- $\quad$ igualmente, nada comprova que a falta do modelo heterossexual acarreta perda de referenciais a tornar confusa a identidade de gênero. Diante de tais resultados, não há como prevalecer o mito de que a homossexualidade dos genitores gere patologias nos filhos;

- $\quad$ nada justifica a estigmatizada visão de que a criança que vive em um lar homossexual será socialmente rejeitada ou haverá prejuízo a sua inserção social.

Aqueles que não consideram possível a adoção por parceiros homossexuais, utilizam-se de argumentos desprovidos de fundamentação jurídica, filosófica e científica. Repita-se, sustentam que faltariam referenciais de ambos os sexos para a formação e desenvolvimento da personalidade do adotando, o que possibilitaria a discriminação da criança no ambiente escolar e comunitário, dentre outros (GAMA, 2008, p. 436).

Parece-nos que identificar indevidamente os vínculos homoparentais como promíscuos, é que gera a falsa ideia de que não se trata de um ambiente saudável para o bom desenvolvimento do adotado. Assim, a insistência em rejeitar a regulamentação da adoção por homossexuais tem por justificativa indisfarçável e preconceituosa (MEDINA, 2008, p. 324). Pura homofobia, muitas vezes disfarçada, muitas vezes escancarada.

A simples existência de estudos para garantir a inexistência de problemas para as crianças adotadas por casais homossexuais, que podem desenvolver-se tão bem quanto as adotadas por casais heterossexuais, já denota enorme grau de homofobia. 0 ar- gumento inicial e preconceituoso, combatido pelos estudos citados, é o de que toda criança necessita de um lar composto por pai e mãe, portanto um lar saudável, sob o risco de tornar-se ela mesma homossexual ou, quando nada, desequilibrada. Esse argumento é tão pueril que deveria ser objeto de riso, não de estudos da comunidade científica, que tem mais o que fazer. Em primeiro lugar, se a criança adotada por homossexuais corre o risco de se tornar homossexual ou desequilibrada mental, muito mais risco corre a criança adotada por casais heterossexuais, uma vez que a maioria esmagadora de homossexuais e desequilibrados mentais é oriunda de lares heterossexuais. Em segundo lugar, qual o problema de uma criança se tornar homossexual? O cancro na pele da sociedade não é a homossexualidade, mas a homofobia.

Muitos afirmam, com razão, não haver impedimento constitucional para que o direito de adoção seja concedido a duas pessoas que não estejam casadas ou que vivam em união estável. Vozes importantes da doutrina, já há algum tempo, têm-se posicionado firmemente neste sentido, como Lobo (2007, p. 258 ${ }^{17}$, Almeida e Rodrigues Júnior, Dias (2010, p. 438) ${ }^{18}$, Farias e Rosenvald, bem como Gama (2008, p. 436-437) ${ }^{19}$.

Entender de modo diverso e não reconhecer a paternidade homoparental, além da flagrante inconstitucionalidade, é retroagir um século ressuscitando a perversa classificação do Código Civil de 1916, que tratava os filhos de forma diferenciada e discriminatória.

17 Para Paulo Lobo, inexiste fundamentação científica a afirmar que a filiação adotiva deva imitar o padrão heterossexual de família nuclear com as figuras bem claras de pai e mãe, de modo a assim garantir a boa formação da criança.

18 Para Maria Berenice Dias, para que seja deferida a adoção exige-se apenas a presença de reais vantagens para 0 adotado, desde que o pedido se funde em motivos legítimos. Dessa forma é irrelevante a forma do arranjo familiar na qual a criança será inserida.

19 Para Guilherme Gama, a razão da incidência dos direitos fundamentais nas relações privadas, bem como diante da textura aberta do sistema jurídico atual, deve-se levar em conta o melhor interesse da criança e do adolescente, admitindo-se a adoção em favor de pessoas do mesmo sexo. 
Velar pelo melhor interesse da criança e do adolescente é lhes garantir direito à vida, à saúde, à alimentação, à convivência familiar, é possibilitar-lhes a inserção em lar, até porque a adoção é ato genuíno de amor, de humanidade, de entrega, de solidariedade e não cabe ao Estado impedir ou dificultar, por razões hipócritas e desprovidas de fundamentação jurídica, que as crianças e adolescentes colocados em adoção encontrem uma família.

Claro que, como em toda adoção, deverão ser avaliadas as circunstâncias relacionadas ao bom e adequado ambiente de convívio entre os parceiros, bem como se a medida não é incompatível com a natureza do relacionamento (art. $29 \mathrm{ECA}$ ), além do grau de afetividade e afinidade entre a criança ou adolescente e os possíveis interessados, de modo a afastar ou minorar as consequências, acaso negativas, decorrentes da medida (art. 28, §2 ${ }^{\circ}$ ECA).

Como bem lembra Veloso (2002, p. 432), “o princípio capital norteador do movimento de renovação do Direito de Família é fazer prevalecer, em todos os casos, o bem da criança; valorizar e perseguir o que melhor atender aos interesses do menor".

A maior visibilidade e melhor aceitabilidade das famílias homoafetivas tornam impositivo o estabelecimento do vínculo jurídico paterno-filial com ambos os genitores, ainda que sejam dois pais ou duas mães. Vetar a possibilidade de juridicizar essa realidade só traz prejuízos ao filho, que não terá qualquer direito em relação àquele que de fato exerce o poder familiar, isto é, desempenho com todos os deveres inerentes a função de pai ou mãe.

Negar a possiblidade de adoção ao par homoafetivo é deixar a realidade encoberta pelo véu da homofobia (DIAS, 2010, p. 354). A Ministra Carmen Lúcia Antunes Rocha $^{20}$, na anteriormente citada decisão do STF, assim se manifestou acerca da união homoafetiva:

20 STF: Ação Direta de Inconstitucionalidade n. 4277/Arguição de Descumprimento de Preceito Fundamental n. 132.
É certo; nem sempre a vida é entendível. E pode-se tocar a vida sem se entender; pode-se não adotar a mesma escolha do outro; só não se pode deixar de aceitar essa escolha, especialmente porque a vida é do outro e a forma escolhida para se viver não esbarra nos limites do Direito. Principalmente, porque o Direito existe para a vida, não a vida para o Direito.

Por sua vez, excerto do voto do Ministro Luiz Fux, no mesmo julgado:

\begin{abstract}
Canetas de magistrados não são capazes de extinguir o preconceito, mas, num Estado Democrático de Direito, detêm o poder de determinar ao aparato estatal a atuação positiva na garantia da igualdade material entre os indivíduos e no combate ostensivo às discriminações odiosas. Esta Corte pode, aqui e agora, firmar posição histórica e tornar público e cogente que o Estado não será indiferente à discriminação em virtude da orientação sexual de cada um; ao revés, será o primeiro e maior opositor do preconceito aos homossexuais em qualquer de suas formas.
\end{abstract}

Atente-se ainda que com mais frequência, no caso de pares formados por duas mulheres, uma se submete à reprodução assistida. Nesse caso, não há como escapar às seguintes indagações: Será mãe somente aquela que se submeteu ao processo procriativo? A parceira que não participou fisicamente do processo reprodutivo, mas dele participou psicologicamente, deve ficar excluída da relação de parentesco, mesmo que o filho só tenha sido concebido porque era a vontade de ambas? Parece que permitir exclusivamente que o vínculo biológico identifique o vínculo jurídico é retroceder e abandonar todas as conquistas do Direito de Família. Como assinala Facchin (2003, p. 123), "não são os laços bioquímicos que indicam a figura do pai, mas sim o cordão umbilical do afeto".

Anota Perlingieri (2001, p. 491) que se o Estado reconhece à família um papel promocional e educativo, voltado ao desenvolvimento da personalidade, qualquer modelo de família merece a proteção do ordenamento jurídico. É um problema não apenas da Lei, mas de costume. Se o costume muda, não cabe ao legislador cristalizar um costume já superado ou mo- 
dificado. E não apenas ao legislador cabe a mudança, deve haver uma reflexão educativa, cultural de modo a difundir o respeito às diversas formas de se empenhar para a família, não apenas o modelo perpetuado pela doutrina cristã.

E continua: o papel do Direito passa pela redescoberta do papel promocional da norma realizada também com a adequação cultural do intérprete e de toda a sociedade civil. A questão não é solucionada apenas pela topografia legislativa, mas na correta individualização do problema. A resposta deve ser buscada em todo o ordenamento jurídico, sem receio do papel residual que o código possa desempenhar, importando ao estudioso ou magistrado observar a pluralidade de fontes, de modo a garantir uma interpretação mais orgânica e justa (PERLINGIERI, 1989, p. 211).

O engessamento das normas de Direito de Família, conforme previsto no atual sistema, deflagram o abismo existente entre a realidade o ideal democrático.

O modelo de Estado Democrático pressupõe um espaço reservado e exclusivo para que as pessoas tomem suas decisões pessoais, tuteladas pela tábua principiológica constitucional e imunes a interferências externas normatizadoras. Como anota Rodotà (1997, p. 5), a antiga virtude do Direito Privado ressurge exatamente no jogo entre regulação e espontaneidade, que ofereça grande espaço para as escolhas e para a autonomia individual.

Devemos, antes e acima de tudo, respeitar a opção pessoal de cada um, a liberdade individual de constituir a forma de relacionamento que melhor aprouver, na legítima tentativa de ser feliz. Devemos lembrar-nos sempre, com muita cautela, que existem razões individuais, pelas quais as pessoas optam por casar ou não casar, pelas quais escolhem modelos familiares não tradicionais, buscam a redesignação sexual, enfim, pelas quais cada qual, conscientemente ou não, trilha o caminho escolhido. A sociedade e o Direito devem evoluir no sentido de oferecer a garantia fundamental de dignidade, de liberdade e de igualdade a todos os indivíduos.

Demais disso, além do processo de despatrimonialização pelo que passa o Direito de Família, há que buscar a funcionalização da família, enquanto instrumento de promoção da dignidade. Nesse sentido, o Direito de Família será instrumento não apenas de proteção ao indivíduo, mas funcionará como garantia das escolhas individuais nas relações afetivas e como limitador ao abuso de poder de um indivíduo sobre o outro.

A adoção da principiologia constitucional, todavia, pressupõe a repolitização do Direito, a preocupação com o conteúdo das normas, a aceitação do pluralismo jurídico e a legitimação da ordem jurídica (AMARAL, 1997, p. 44-45).

O Direito de Família, em sua concepção constitucionalizada, mostra-se como sistema aberto, que se alimenta também da atividade jurisdicional criadora, razão pela qual não pode ser trabalhado como mero ato mecânico de aplicação da Lei, afinal, o sistema jurídico é dialético, argumentativo, não dedutivo (LORENZETTI, 1998, p. 231).

A CR/88 pauta-se pela pluralidade, pela inclusão, pela isonomia, pela igualdade, pela não discriminação. Todavia, a aceitação social e jurídica da família homoafetiva ainda não é plena. A condenação e marginalização da família homoafetiva tem origem religiosa, e este modo de ser no mundo afetivo ainda não foi laicizado (WELTER, 2009, p. 176).

Devemos nos indagar se em nossa sociedade democrática, que se diz inclusiva, os indivíduos que exerçam sua condição sexual de forma irrestrita, têm iguais oportunidades e direitos na construção de sua personalidade e na promoção de sua dignidade. $E$ mais, na construção de sua família.

A rejeição da aceitação da família homoafetiva, segundo Welter (2009, p. 196), causa a objetivação 
humana por negar o direito a tridimensionalidade humana, genética, (des)afetiva e ontológica ${ }^{21}$. Por esse raciocínio, a homoafetividade representa uma forma de ser-no-mundo afetivo, que poderá denotar seu caráter familiar a ser reconhecido juridicamente. A par deste modo de ser em família, existem várias outras acepções de ser-em-família: conjugal, convivencial, monoparental, unipessoal, socioafetiva, anaparental, reconstituída.

Não se pode negar que a realidade do mundo, da história atual, é de que a homoafetividade esteja presente em milhares de vidas, e consequentemente em milhares de lares, em que milhares de indivíduos compartilham e desvelam seus sonhos e desejos em família, inclusive sonhos de filiação já realizados através da adoção e da inseminação artificial (ALMEIDA, 2008, p. 15).

Isto revela que a homoafetividade representa uma classe de indivíduos que o Estado Democrático de Direito tem a missão de também promover, já que a CR/88 não tem a função de expressar e promover a existência de uma homogeneidade cultural, identidade coletiva ou coesão, muito ao contrário, deve garantir, através da carta de direitos fundamentais, a convivência e promoção entre sujeitos de interesses diversos e virtualmente em conflito (FERRAJOLI, 2011).

Neste papel, a hermenêutica constitucional está a nos indicar apenas um caminho: o viés da inclusão do multiculturalismo, com o objetivo de procurar que a realidade da trajetória da vida dos indivíduos esteja sob o manto da proteção do Estado. A possibi-

21 Pela linguagem heideggeriana, o ser humano tem uma abertura de caráter triplo para si, para os outros e para as coisas. Aplicando esse pensamento ao Direito de Família, pode ser dito que a compreensão do ser humano não é efetivada unicamente pelo mundo genético (das coisas, dos objetos), mas, sim, compreendido como um acontecer no mundo genético (abertura as coisas), num mundo afetivo e desafetivo (abertura: afeto, ou fechamento: desafeto, para os outros ) e mundo ontológico (abertura para si). É por isso que pela hermenêutica filosófica, o ser humano deixa der ser objetificado, coisificado, porque ele perde o viés solitário, unitário, a visão monocular da normatização genética, para ser compreendido como um ser em sua totalidade, no acontecer de sua tridimensionalidade, genética, afetiva e ontológica. lidade de enxergar e outorgar iguais oportunidades e direitos a indivíduos que representem diversos matizes deve ser o desafio do Estado plural. Não há de fato regime democrático, quando é exigido que todos os interesses e valores sejam aceitos como absolutos, eternos, iguais, formais; enquanto não formos capazes de conviver e promover a diversidade, os valores do outro.

A compreensão do Direito no Estado Democrático há de ser um constante construir-se, um espiral de diálogo, discursivo e aberto aos modos de ser-no-mundo tridimensional. Não há que exigir dos indivíduos homoafetivos que se dispam de suas individualidades para ser aceitos como iguais, haja vista que a igualdade constitucional necessariamente deve ser substancial, hermenêutica, democrática, que reclame a aceitação da igualdade e da diversidade tridimensional, sob pena de deflagrar tratamento preconceituoso àquele que encontrou na homoafetividade o seu jeito de ser (DIAS, 2011).

Esperam, os indivíduos que optam pela constituição da família homafetiva, a concretização das aspirações principiológicas propostas pelo Estado Democrático de Direito: a salvaguarda da pluralidade, a promoção da dignidade da pessoa humana, a preservação da igualdade, a não discriminação.

Embora a decisão do STF represente grande avanço contra o preconceito e a maldade, não põe fim ao problema, visto que os direitos dos companheiros homossexuais devem ainda ser regulamentados pelo legislador.

As escolhas de projeto e condução de vida dos indivíduos não podem ser tolhidas no Estado Democrático de Direito, que só se realiza permitindo a inclusão de projetos de vida diversos, que reflitam uma sociedade pluralista. Apenas desta forma, concretizar-se-á a sociedade democrática (GALUPPO, 2002, p. 210). 
Por sua vez, não há pluralismo sem diversidade e tolerância (OLIVEIRA, 1997, p. 160). O Direito de uma sociedade democrática deve realizar, na medida do possível, o projeto de vida da maioria e, concomitantemente, preservar os projetos de vida alternativos ${ }^{22}$.

A abertura do Direito para o futuro significa que sempre estaremos aptos a resgatar o projeto moderno, que vem sendo construído de maneira a atualizar a substância normativa inesgotável do sistema de Direito (CHAMON JÚNIOR, 2006, p. 70).

\section{CONCLUSÃO}

O objetivo deste trabalho foi analisar a ampla possibilidade de adoção por pares homossexuais, diante do reconhecimento pelo STF de efeitos jurídicos da união estável à união familiar homoafetiva. Para tanto, foi analisada de forma muito breve a evolução histórica da adoção, seu tratamento legal no Brasil, comentamos o perfil da adoção em Portugal e a ideia contemporânea de família, segundo nossa concepção.

A sistematização dada ao trabalho procurou buscar as origens da adoção e mostrar que a família, independentemente dos contornos que assuma, deve promover o pleno desenvolvimento de seus membros e, diante dessa concepção, demonstrar a ausência de qualquer prejuízo à adoção por par homoafetivo.

Verificou-se que ainda é grande a resistência em aceitar a possibilidade de homossexuais ou parceiros do mesmo sexo habilitarem-se para a adoção. Foram analisadas as dúvidas suscitadas quanto ao sadio desenvolvimento da criança. Buscou-se demonstrar que há equivocada crença de que a falta de referências comportamentais de ambos os sexos possa acarretar sequelas de ordem psicológica e dificuldades na identificação sexual do adotado.

22 Para Galuppo o projeto de vida da maioria está ligado à dimensão da facticidade, enquanto o projeto de vida da minoria conecta-se ao plano da validade.
Atentando para uma hermenêutica constitucionalizada, vislumbrando a pluralidade de núcleos familiares, ou seja, as entidades familiares não se resumem àquelas indicadas no rol constitucional, não se justifica a limitação da adoção conjunta apenas aos núcleos familiares formados pelo casamento e união estável heterossexual (ALMEIDA; RODRIGUES, 2010, p. 234). Nesse sentido, forte nos princípios constitucionais da igualdade, não discriminação, dentre outros, entende-se que também aos pares homoafetivos deve ser concedido o direito da adoção conjunta ${ }^{23}$.

O Estatuto da Criança e do Adolescente autoriza a adoção por uma única pessoa, não fazendo qualquer restrição quanto a sua orientação sexual. Portanto, não é difícil prever a hipótese de um homossexual que, ocultando sua preferência sexual, venha a pleitear e obter a adoção de uma criança, trazendo-a para conviver com quem mantenha um vínculo afetivo estável. Nessa situação, quem é adotado por um só dos parceiros não pode desfrutar de qualquer direito com relação àquele que também reconhece como verdadeiramente seu pai ou sua mãe. Ocorrendo a separação do par ou a morte do que não é legalmente o genitor, nenhum benefício o filho poderá usufruir. Não pode pleitear qualquer direito, nem alimentos, nem benefícios de cunho previdenciário ou sucessório. Sequer o direito de visita é regulamentado, mesmo que detenha a posse do estado de filho, tenha igual sentimento e desfrute da mesma condição frente a ambos. 0 amor para com os pais em nada se diferencia pelo fato de eles serem do mesmo ou de diverso sexo. Ao se arrostar tal realidade, é imperioso concluir que, de forma paradoxal, o intuito de resguardar e preservar a criança ou o adolescente resta por lhe subtrair a

23 Vale lembrar que o art. 6 do ECA prevê que: "Na interpretação desta Lei levar-se-ão em conta os fins sociais a que ela se dirige, as exigências do bem comum, os direitos e deveres individuais e coletivos, e a condição peculiar da criança e do adolescente como pessoas em desenvolvimento". 
possibilidade de usufruir direitos que de fato possui (DIAS, 2012).

Cada vez mais, indivíduos homossexuais estão assumindo sua orientação sexual e buscando a realização do sonho de estruturar uma família com a presença de filhos. Vã é a tentativa de negar ao par o direito à convivência familiar, ou deixar de reconhecer a possibilidade de crianças viverem em lares homossexuais.
A adoção não pode estar condicionada à preferência sexual ou à realidade familiar do adotante, sob pena de infringir-se o princípio do melhor interesse da criança, o princípio à dignidade humana, que se sintetiza no princípio da igualdade e na vedação de tratamento discriminatório de qualquer ordem.

\section{REFERÊNCIAS}

ALMEIDA, Renata Barbosa. RODRIGUES JÚNIOR, Walsir Edson. Direito das famílias. Rio de Janeiro: Lumen Juris, 2010.

ALMEIDA, Suzana. 0 respeito pela vida (privada e) familiar na jurisprudência do tribunal europeu dos direitos do homem: a tutela da novas formas de família. Coimbra: Coimbra, 2008.

AMARAL, Francisco. Direito civil: introdução. 5. ed., Rio de Janeiro: Renovar, 2003.

BORRILLO, Daniel. Homofobia - história e crítica de um preconceito. Belo Horizonte: Autêntica, 2010.

CHAMON JUNIOR, Lúcio Antônio. Teoria geral do direito moderno: por uma reconstrução crítico-discursiva na alta modernidade. Rio de Janeiro: Lumen Juris, 2006.

COULANGES, Fustel. A cidade antiga. Lisboa: Livraria Clássica, 1950.

DIAS, Maria Berenice. Manual de direito das famílias. Porto Alegre: Livraria do Advogado, 2005.

DIAS, Maria Berenice. Convivendo com a diversidade. Disponível em: www.intrannet.mp. rs.gov.br. Acesso em: 25 fev. 2011.
DUARTE PINHEIRO, Jorge. Direito de família contemporâneo. 3. ed., Lisboa: A.A.F.D., 2011.

FACCHIN, Luiz Edson. Teoria crítica do direito civil. Rio de Janeiro: Renovar, 2003.

FARIAS, Mariana de Oliveira; MAIA, Ana Claudia Bortolozzi. Adoção por homossexuais - A família homoparental sob o olhar da psicologia jurídica. Porto Alegre: Juruá, 2008.

FERRAJOLI, Luigi. Pasado y futuro del estado de derecho. Disponível em: www.ucm.es/fltml. Acesso em: $21 \mathrm{fev} .2011$.

GALUPPO, Marcelo Campos. Igualdade e diferença: 0 estado democrático de direito a partir do pensamento de Habermas. Belo Horizonte: Mandamentos, 2002.

GAMA, Guilherme Calmon Nogueira da. Direito civil: família. São Paulo: Atlas, 2008

LÔBO, Paulo. Direito civil: famílias. Rio de Janeiro: Saraiva, 2007.

LORENZETTI, Ricardo Luis. Fundamentos do direito privado. Tradução Vera Maria Jacob de Fradera. São Paulo: Revista dos Tribunais, 1998. 
MÚRIAS, Pedro; BRITO, Miguel Nogueira de. Um sim e um não sobre o casamento entre pessoas do mesmo sexo. Lisboa: Entrelinhas, 2008.

MEDINA, Graciela. Uniones de hecho homosexuales. Buenos Aires: Rubinzal-Culzoni, 2008.

OLIVEIRA, Marcelo Andrade Cattoni de. Tutela jurisdicional e estado democrático de direito. Belo Horizonte: Del Rey, 1997.

PEREIRA, Rodrigo da Cunha. Princípios norteadores para o direito de família. Belo Horizonte: Del Rey, $2006 a$.

PEREIRA, Rodrigo da Cunha. A ética da convivência familiar e sua efetividade no cotidiano dos tribunais. Rio de Janeiro: Forense, 2006b.

PEREIRA, Rodrigo da Cunha. Direito e Psicanálise. In: GALUPPO, Marcelo Campos (org). O Brasil que queremos: reflexões sobre o estado democrático de direito. Belo Horizonte: PUCMINAS, 2006c.

PERLINGIERI, Pietro. Perfis do direito civil: introdução ao direito civil constitucional. Tradução Maria Cristina de Cicco. 2. ed., Rio de Janeiro: Renovar, 2002.
PERLINGIERI, Pietro. Il diritto civile nella legalità costituzionale. Napoli: Edizioni Scientifiche, 2001.

PERLINGIERI, Pietro. Scuole, tendenze e metodi: problemi del diritto civille. Napoli: Edizioni Scientifiche, 1989.

RODOTÀ.Stefano. Lo specchio di Stendhal: Riflessioni sulla riflessioni dei privatisti. Rivista Critica del Diritto Privato, Napoli: Jovene, 1997

VEloSO, Zeno. Código Civil Comentado. São Paulo: Atlas, v. 7., 2002.

VILLELA, João Baptista. Sobre a igualdade de direitos entre homens e mulheres. Revista da Faculdade de Direito da UFMG, Belo Horizonte, 1993.

VENOSA, Silvio de Salvo. Direito Civil. São Paulo: Atlas, vol. V, 2005.

WELTER, Belmiro Pedro. Teoria tridimensional do direito da família. Porto Alegre: Livraria do Advogado, 2009. 